\title{
Comparison of Monomethylhydrazine/ Hydroxypropylcellulose and Hydrocarbon/Silica Gels
}

\author{
R. Arnold*, P. H. S. Santos ${ }^{\dagger}$, M. deRidder ${ }^{\ddagger}$, O. H. Campanella ${ }^{\S}$, and W. E. Anderson \\ Purdue University, \\ West Lafayette, IN 47907, USA
}

\begin{abstract}
Experimental studies have been performed to investigate rheology and droplet burning with different types of gelled propellants. Monomethylhydrazine has been gelled with organic hydroxypropylcellulose. JP-8 and RP-1 hydrocarbon gels have been produced with inorganic fumed silica particles. Rheological characterization showed the differences in terms of viscosity and yield stress behavior due to different types of gelling agents. Herschel-Bulkley and Carreau-Yasuda models have been used to characterize the gels with inorganic and organic gelling agents, respectively. First experiments with the Monomethylhydrazine/hydroxypropylcellulose gels showed a typical swelling process during combustion with a flexible viscous droplet surface. Contrary to that, the hydrocarbon/silica gels burned while a rigid silica structure was built, which remained unburned. Burning drop measurements have been compared to the $d^{2}$-squared law.
\end{abstract}

\section{Nomenclature}

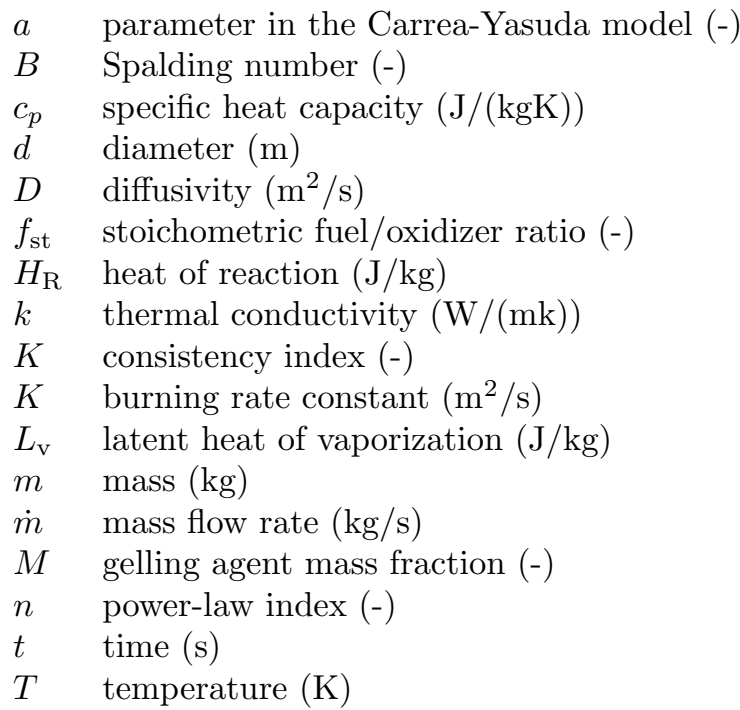

$\begin{array}{ll}\dot{\gamma} & \text { shear rate }(1 / \mathrm{s}) \\ \eta & \text { viscosity }(\mathrm{Pa} \cdot \mathrm{s}) \\ \eta_{0} & \text { viscosity for shear rates } \rightarrow 0(\mathrm{~Pa} \cdot \mathrm{s}) \\ \eta_{\infty} & \text { viscosity for shear rates } \rightarrow \infty(\mathrm{Pa} \cdot \mathrm{s}) \\ \rho & \text { density }\left(\mathrm{kg} / \mathrm{m}^{3}\right) \\ \sigma_{0} & \text { yield stress }(\mathrm{Pa}) \\ & \\ \text { Subscript } \\ 0 & \text { initial condition } \\ \infty & \text { ambient } \\ \mathrm{b} & \text { burning } \\ \mathrm{d} & \text { droplet } \\ \text { eff } & \text { effective } \\ \mathrm{g} & \text { gas } \\ \text { gel } & \text { gelling agent } \\ \text { liq } & \text { liquid } \\ \mathrm{s} & \text { surface }\end{array}$

\section{Introduction}

CELs feature important advantages in comparison to liquid or solid propellants. Due to the solid-like Gbehaviour, gels are comparably easy to handle, which is especially important for toxic fluids. The

\footnotetext{
*Post Doctoral Scientist, Department of Aeronautics and Astronautics, AIAA Member, Email: arnold17@purdue.edu

${ }^{\dagger}$ Graduate Research Assistant, Department of Agricultural and Biological Engineering, Email: psantos@purdue.edu

${ }^{\ddagger}$ Post Doctoral Scientist, Department of Aeronautics and Astronautics, AIAA Member, Email: mderidde@purdue.edu

§Professor, Department of Agricultural and Biological Engineering, Email: campa@purdue.edu

『Associate Professor, Department of Aeronautics and Astronautics, AIAA Senior Member, Email: wanderso@purdue.edu
} 
high initial viscosity ensures good leakage and spill characteristics. When shear stress is applied, gels can be pumped, injected and burned like conventional liquid fuels. Performance of gelled propellant is comparable to the performance of liquids. Previous investigations concentrated on gelled hydrocarbon fuels and on gelled monopropellants like MMH (Monomethylhydrazine) and UDMH (Unsymmetrical dimethylhydrazine). A matter of particular interest is the gelling of oxidizers like WFNA (White fuming nitric acid) and IRFNA (Inhibited red fuming nitric acid) ${ }^{1,2}$ Together with gelled MMH, these oxidizers can be used for the propulsion of hypergolic gelled rocket engines. With metallic powder addition, the most promising gelled hypergolic propellant combinations for future rocket applications are $\mathrm{MMH} / \mathrm{Al} / \mathrm{IRFNA}$ and $\mathrm{MMH} / \mathrm{Al} / \mathrm{NTO}$ (Nitrogen tetroxide). The first successful flight of a missile in 1999 used a carbon loaded MMH gel and a gelled IRFNA oxidizer, which showed the technical readiness of gelled propellant technology. ${ }^{3}$

\section{A. Monomethylhydrazine/hydroxypropylcellulose gels}

Hydrazine is widely used for upper stage application and small satellite propulsion. Especially the hypergolic combination of monomethylhydrazine and nitrogen tetroxide is a matter of particular interest. For example, $\mathrm{MMH} / \mathrm{NTO}$ is used in the orbital maneuvering system (OMS) and the reaction control system (RCS) of the Space Shuttle orbiter. MMH/NTO is also used in the re-ignitable upper stage engine Aestus of the European Ariane 5 launcher.

Methylhydrazine, also called monomethylhydrazine, has been used within the present study as a propellant. $\mathrm{MMH}\left(\mathrm{CH}_{3} \mathrm{~N}_{2} \mathrm{H}_{3}\right)$ has a lower freezing point than hydrazine $\left(\mathrm{N}_{2} \mathrm{O}_{4}\right)$, which favors it for applications in a low temperature environment. Table 1 summarizes typical properties of MMH. ${ }^{4}$

Table 1. MMH properties (at $298 \mathrm{~K}$ )

\begin{tabular}{lr}
\hline \hline boiling point $(\mathrm{K})$ & 360.80 \\
flash point, min. $(\mathrm{K})$ & 290 \\
vapor pressure $(\mathrm{kPa})$ & 6.6 \\
density, liquid $\left(\mathrm{g} / \mathrm{cm}^{3}\right)$ & 0.87 \\
viscosity, liquid $(\mathrm{mPa} \cdot \mathrm{s})$ & 0.775 \\
heat capacity, liquid $(\mathrm{J} /(\mathrm{gK}))$ & 2.93 \\
heat of vaporization, at normal bp $(\mathrm{kJ} / \mathrm{mol})$ & 37.2 \\
heat of combustion, min. $(\mathrm{MJ} / \mathrm{kg})$ & 28.3 \\
\hline \hline
\end{tabular}

KLUCEL@ hydroxypropylcellulose (HPC), which is a nonionic watersoluble cellulose ether, has been used as a gelling agent. HPC is mainly used as a thickener for adhesives, paint removers and food, as well as a binder in chemical and pharmaceutical industry. In the past, cellulose based derivatives like hydroxypropylcellulose (HPC), hydroxyethylcellulose (HEC), and hydroxyalkylcellulose (HAC) have been used successful to gel monomethylhydrazine. ${ }^{1,5,6}$ KLUCEL $\AA$ HPC is an organic gelling agent with a bulk density of $0.5 \mathrm{~kg} / \mathrm{l}$. It vaporizes within the temperature range of $520 \ldots 770 \mathrm{~K}$. Due to very low ash content and the absence of organic remainders, HPC burns completely together with the liquid part of the gel..$^{7,8}$ This is contrary to gels with inorganic gelling agents like fumed silica $\left(\mathrm{SiO}_{2}\right)$, where the silica remains unburned at the end of the gel combustion process. ${ }^{2,9}$

Investigations have shown that the addition of HPC to the MMH easily creates chunks or "fish eyes" since the tendency of the cellulose particles is to stick together instead to dissolve in the liquid. To avoid the formation of "fish eyes", the HPC powder has been added slowly in steps of $1 \%$, followed by an intensive period of stirring.

Like other water-soluble materials, HPC absorbs the moisture from the air. To avoid atmospheric moisture in the mixture, the mixing container is continuously purged with nitrogen.

Unlike cellulose, HPC is soluble in aqueous solutions. Due to the substitution of some hydroxyl groups in the glucose units by hydroxypropyl groups, HPC as well as other cellulose ethers are soluble in water and in organic solutions. In general, HPC can be dissolved in those solvents at room temperature and its solubility decreases as temperature increases. The dissolution in aqueous medium occurs due to the hydration of the high molecular weight cellulose backbone. The ether groups added to the cellulose molecule reduce the inter-molecular interaction, allowing the polysaccharide chain to interact with the molecules of the liquid. 
The polysaccharide chains expand and uncoil, resulting in the formation of an entangled network and an increase in the solution viscosity.

Gels with KLUCEL $\AA$ show little or no thixotropic behavior in comparison to highly-thixotropic gels featuring an inorganic gelling agent like $\mathrm{SiO}_{2}$. The viscosity is reduced when shear is applied to the gel, however, the viscosity returns to the original value when the shear stress is removed. ${ }^{7}$

\section{B. Hydrocarbon/silica gels}

Two different hydrocarbon fuels have been gelled with fumed silica: Rocket propellant RP-1 and jet propellant JP-8. RP-1 is a rocket propellant, which powers the first-stage boosters of the Delta and Atlas-Centaur rockets, and was also used in the first stage of the Saturn V. Due to the high density in comparison with high-energetic liquid hydrogen, the propellant combination RP-1/liquid oxygen is also used in many Russian booster engines (RD-170, RD-180). ${ }^{10}$ JP-8 (jet propellant; NATO code F-34) is the U.S. Air Force primary jet fuel, replacing JP-4 in 1995 because of its less flammable character, better safety and higher combat survivability.

Untreated fumed silica $\mathrm{SiO}_{2}(\mathrm{CAB}-\mathrm{O}-\mathrm{SIL} \cap$ grade $\mathrm{M}-5)$ has been used to gel the hydrocarbon propellants. Due to hydrogen bonds between single silica aggregates in a dispersed liquid system, increased viscosity and thixotropic behavior is the result. When burning inorganic silica gels, the particles remain unburned, which is different from gels which use organic gelling agents like HPC.

An acoustic high-shear mixing process has been used to gel the hydrocarbon fuels JP-8 and RP-1. ${ }^{11}$ A detailed description of the hydrocarbon/silica gelling process can be taken from a previous Purdue University publication. $^{9}$

\section{Rheological characterization}

\section{A. Non-Newtonian fluids}

Gels envisaged for the application in rocket and airbreathing propulsion systems have to show a shearthinning behavior to provide a reasonable pressure drop when pumped from the storage tank to the chamber. Figure 1 depicts the behavior of shear stress and viscosity as a function of shear rate for different Newtonian and non-Newtonian fluids. ${ }^{12}$

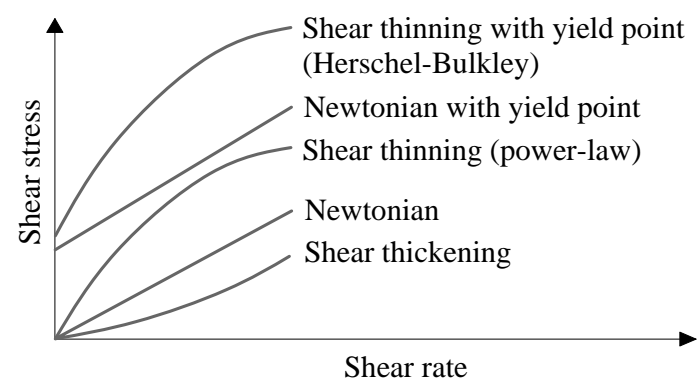

(a) Shear stress vs. shear rate

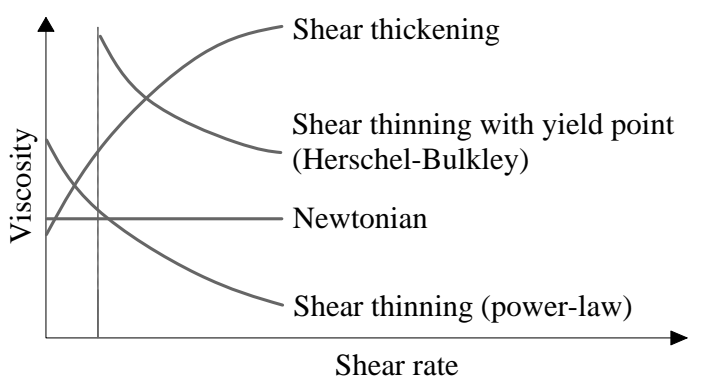

(b) Viscosity vs. shear rate

Figure 1. Newtonian and non-Newtonian fluids

In general, for any liquid the dynamic viscosity $\eta$ can be expressed as a function of shear stress $\sigma$ and shear rate $\dot{\gamma}$ :

$$
\eta=\frac{\sigma}{\dot{\gamma}}
$$

For a non-Newtonian liquid the viscosity $\eta$ is dependent on the applied shear rate $\dot{\gamma}$. For the characterization of Newtonian and non-Newtonian fluids without a yield point, the power-law model (Ostwald-de Waele model) is the most common correlation: ${ }^{13}$

$$
\eta=K \dot{\gamma}^{n-1}
$$

$K$ is the consistency index, whereas $n$ gives the power-law index of the fluid. For $n=1$ equation (2) 
describes a Newtonian fluid. However, shear thinning behavior is given for a power-law index $0<n<1$, and shear thickening (dilatant behavior) for $n>1$.

The Herschel-Bulkley model (HB) is a simple description for non-linear gels which also consider a yield stress $\sigma_{0}$ for low and medium shear rates: ${ }^{13}$

$$
\eta=\eta_{0}+K \dot{\gamma}^{n-1}
$$

Finally, an extended version of the Herschel-Bulkley equation (HBE) takes into account the minimum viscosity $\eta_{\infty}$ at very high shear rates: ${ }^{13,14}$

$$
\eta=\eta_{0}+K \dot{\gamma}^{n-1}+\eta_{\infty}
$$

Alongside the HBE, a further common model was provided from Carreau-Yasuda which also considers viscosities at very low $(\eta \rightarrow 0)$ and very high $(\eta \rightarrow \infty)$ shear rates. However, this model neglects the existence of yield stress:

$$
\eta=\eta_{\infty}+\frac{\eta_{0}-\eta_{\infty}}{\left\{1+(K \dot{\gamma})^{a}\right\}^{\frac{1-n}{a}}}
$$

With the HBE or the Carreau-Yasuda models viscosities at typical rocket engine and ramjet injection conditions with shear rates above $10^{5} \mathrm{~s}^{-1}$ can be considered, whereas the HB model would predict much too low viscosities at these conditions with values far below the viscosity of the pure liquid. ${ }^{15}$

\section{B. Results and discussion}

Rheological measurements have been performed using a rotational rheometer, applying shear rates up to $1000 \mathrm{~s}^{-1}$. Different configurations (parallel-plate and cone-and-plate) have been used to meet the varying characteristics of the gels.

To characterize the concentration of the gels, the mass fraction $M$ describes the gelling agent amount $m_{\text {gel }}$ in comparison to the total propellant mass, given by the mixture of liquid $m_{\text {liq }}$ and gelling agent $m_{\text {gel }}$ :

$$
M=\frac{m_{\mathrm{gel}}}{m_{\mathrm{liq}}+m_{\mathrm{gel}}}
$$

Figure 2 depicts the viscosity of the hydrocarbon and $\mathrm{MMH}$ gels for a gelling agent amount of $M=4 \%$. The different behavior of the $\mathrm{MMH} / \mathrm{HPC}$ and hydrocarbon/silica gels is clearly visible. Gelled JP-8 and RP-1 show a comparable high viscosity for low shear rates. However, due to thixotropic effects the viscosity decreases with a comparatively steep slope for increasing shear rates. After the hydrogen bond system of the silica gels is destroyed due to applied shear, the viscosity is reduced significantly. The MMH/HPC gel shows a Newtonian plateau for low shear rates where the applied shear rate has no considerable influence on the gel viscosity. For higher shear rates a reduction in viscosity can be observed. The viscosity reduction with increasing shear is less in comparison to the silica gels. For shear rates higher than approximately $0.1 \mathrm{~s}^{-1}$ the MMH gel features a higher

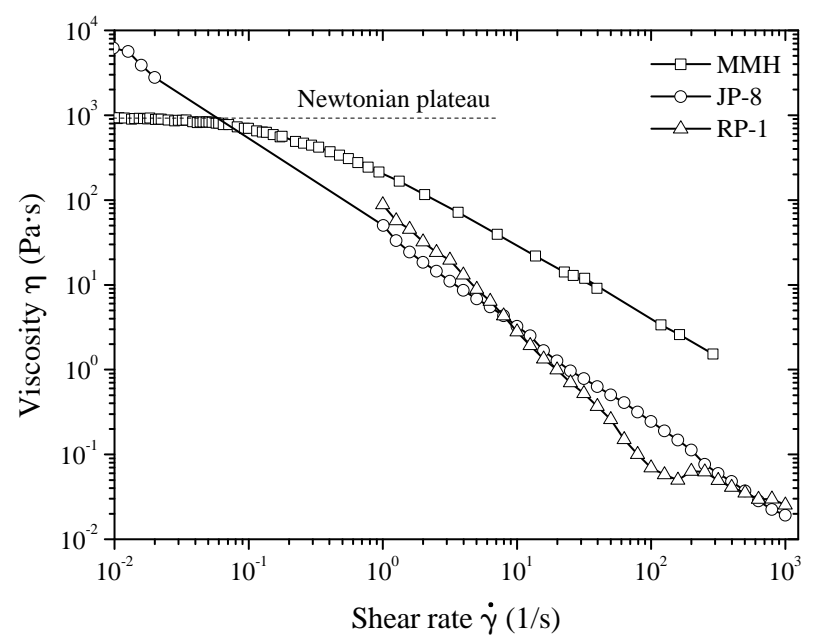

Figure 2. Viscosity as a function of shear rate $(M=4 \%)$ viscosity than the hydrocarbon gels with the same amount of gelling agent. Contrary to that, the viscosity of the pure $\mathrm{MMH}$ is $0.775 \mathrm{mPa} \cdot \mathrm{s},{ }^{4}$ the viscosities of $\mathrm{JP}-8$ and $\mathrm{RP}-1$ have been measured to $1.32 \mathrm{mPa} \cdot \mathrm{s}$ and $1.68 \mathrm{mPa} \cdot \mathrm{s}$, respectively. ${ }^{9}$

Investigations at low stress levels have shown no yield stress for the $\mathrm{MMH} / \mathrm{HPC}$ gel, as depicted in figure 3 (a). Even for a small applied stress, the gel sample flows with a low shear rate. A viscosity of approximately $950 \mathrm{~Pa} \cdot \mathrm{s}$, which is in the Newtonian-plateau region (see figure 2) was measured for small

4 of 10

American Institute of Aeronautics and Astronautics 
stresses, which shows clearly the absence of a yield stress, which is typical for gels with cellulose derivatives as a gelling agent. On the other hand, the hydrocarbon/silica gels feature a distinct yield stress behavior, as depicted in figure 3 (b). After passing the yield point, the shear rate raises steeply when the fluid starts to flow.

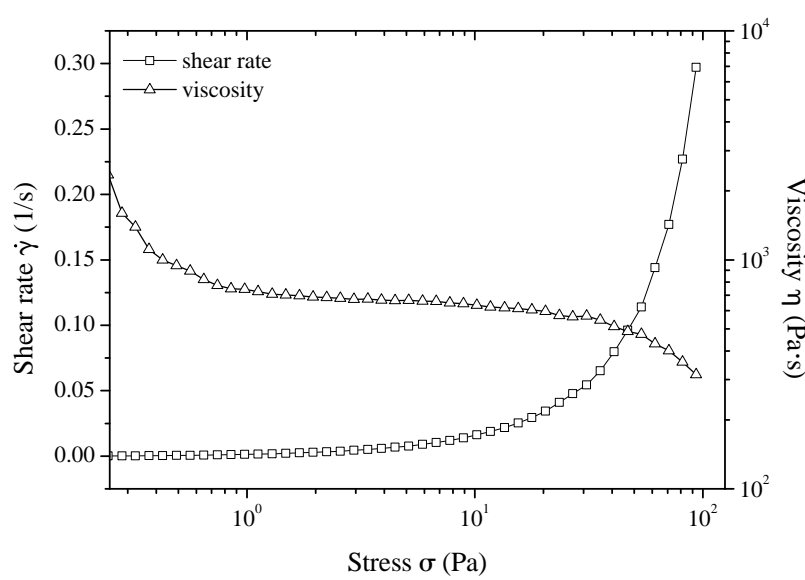

(a) MMH gel

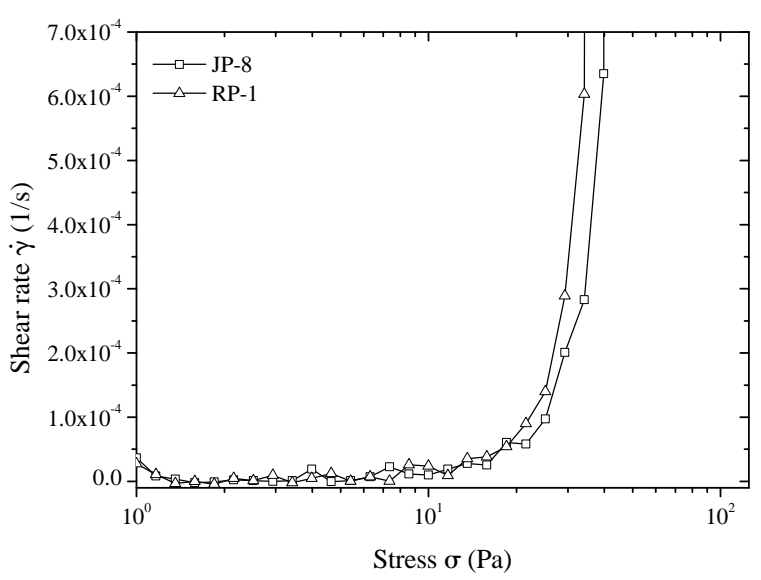

(b) Hydrocarbon gels

Figure 3. Shear rate as a function of stress $(M=4 \%)$

Due to the yield stress behavior, the Herschel-Bulkley model (HBE) following equation (4) has been used to describe the hydrocarbon/silica gels. Table 2 summarizes the HBE parameters $\sigma_{0}, K, n$, and $\eta_{\infty}$. For this analysis, the assumption of an agreement of viscosity for high shear rates, $\eta_{\infty}$, and viscosity of the pure liquids has been done.

For the MMH/HPC gels without yield stress, the Carreau-Yasuda model has been applied (see equation (5)). Table 3 features the parameters $\eta_{0}, \eta_{\infty}, K, n$, and $a$ of the Carreau-Yasuda model. The steeper slope of the viscosity curve for the hydrocarbon/silica gels (see figure 2) is reflected in a much lower powerlaw index $n$. Due to the highly thixotropic behaviour of the hydrocarbon/silica gels even negative numbers of the power-law index occur.

Table 2. HBE parameters for gelled hydrocarbons $(M=4 \%)$

\begin{tabular}{lcc}
\hline \hline & $\mathrm{JP}-8$ & $\mathrm{RP}-1$ \\
\hline$\sigma_{0}(\mathrm{~Pa})$ & 22 & 18 \\
$K\left(\mathrm{~Pa} \cdot \mathrm{s}^{n}\right)$ & 27.13 & 67.64 \\
$n(-)$ & -0.85 & -0.56 \\
$\eta_{\infty}(\mathrm{mPa} \cdot \mathrm{s})$ & 1.32 & 1.68 \\
\hline \hline
\end{tabular}

Table 3. Carreau-Yasuda parameters for gelled MMH $(M=4 \%)$

\begin{tabular}{lc}
\hline \hline$\eta_{0}(\mathrm{~Pa} \cdot \mathrm{s})$ & 950 \\
$\eta_{\infty}(\mathrm{mPa} \cdot \mathrm{s})$ & 0.775 \\
$K\left(\mathrm{~Pa} \cdot \mathrm{s}^{n}\right)$ & 4.76 \\
$n(-)$ & 0.09 \\
$a(-)$ & 1.07 \\
\hline \hline
\end{tabular}

\section{Droplet burning}

Since the combustion characteristics of gelled propellants are still not fully understood, a number of investigations have been performed in the past. The Israel Institute of Technology (Technion) has shown results from droplets of water gels ${ }^{16}$ and hydrocarbon based gels (kerosene, ${ }^{17} \mathrm{JP}-5,{ }^{18,19} \mathrm{JP}-8^{2},{ }^{20}$ ), indicating that the amount of the added gelling agent has a strong influence on the burning behavior of the droplets in comparison to the ungelled pure liquid.

In general, the mass balance for a droplet featuring the mass $m_{\mathrm{d}}(t)$ during combustion is given by:

$$
\frac{\mathrm{d} m_{\mathrm{d}}}{\mathrm{d} t}=-\dot{m}
$$

With consideration of the droplet-gas-phase interface energy balance and the assumption of a quasi-steady 
vaporation and burning, a Lewis number of unity and a uniform droplet temperature $T_{\mathrm{d}}$ equal to the boiling temperature of the fluid $T_{\text {boil }}$ it can be written: ${ }^{21}$

$$
\frac{\mathrm{d} d_{\mathrm{d}}^{2}}{\mathrm{~d} t}=-\frac{8 k_{\mathrm{g}}}{\rho_{\mathrm{d}} c_{p, \mathrm{~g}}} \ln (B+1)
$$

$\rho_{\mathrm{d}}$ and $\rho_{\mathrm{g}}$ are the densities of the droplet and the gas, respectively, $k_{\mathrm{g}}$ the thermal conductivity of the gas, $c_{p, \mathrm{~g}}$ the specific heat of the gas, and $B$ is the Spalding transfer number, which represents the enthalpy ratio exiting the gas and entering the droplet during phase transformation processes:

$$
B=\frac{c_{p, \mathrm{~g}}\left(T_{\infty}-T_{\mathrm{s}}\right)+H_{\mathrm{R}} f_{\mathrm{st}} m_{0, \infty}}{L_{\mathrm{v}}}
$$

$T_{\infty}$ and $T_{\mathrm{s}}$ describe the ambient temperature and the droplet surface temperature, respectively, whereas $H_{\mathrm{R}}$ is the heat of reaction, $f_{\mathrm{st}}$ the stoichometric ratio between fuel and oxidizer, $m_{0, \infty}$ the ambient oxygen mass fraction, and $L_{\mathrm{v}}$ the latent vaporization heat of the investigated fuel.

The addition of a gelling agent will change the Spalding number which controls the reaction by changing the heat of vaporization of the droplet. To take into account the influence of the gelling agent on the heating of the droplet, the effective heat of vaporization can be used for the period when the surface temperature and the droplet temperature, $T_{\mathrm{s}}$ and $T_{\mathrm{d}}$ respectively, are not in agreement: ${ }^{22}$

$$
L_{\mathrm{v}, \text { eff }}=L_{\mathrm{v}}+c_{p, \mathrm{~d}}\left(T_{\mathrm{s}}-T_{\mathrm{d}}\right)
$$

In general, diffusion controlled droplet burning can be characterized by a typical $d^{2}$-law, which describes the relation between the total droplet burning time $t_{\mathrm{b}}$ and the initial droplet square diameter $d_{0}^{2}$ before ignition takes place. As it can be seen in equation (8), the present square droplet diameter $d_{\mathrm{d}}^{2}(t)$ is a linear function of the time $t$ with a slope $K$, which is defined as the burning rate constant (see figure 4 ):

$$
K=\frac{8 k_{\mathrm{g}}}{\rho_{\mathrm{d}} c_{p, \mathrm{~g}}} \ln (B+1)
$$

It should be noted that $K$ is only a constant when a steady-state droplet surface temperature is reached. Due to the small mass of the investigated droplets and the high heating rates in this experiment, this assumption is reasonable. By the use of the correlation:

$$
\frac{k_{\mathrm{g}}}{c_{p, \mathrm{~g}}}=\rho_{\mathrm{g}} D
$$

where $D$ describes the diffusivity of oxygen, equation (11) can also be written:

$$
K=\frac{8 D \rho_{\mathrm{g}}}{\rho_{\mathrm{d}}} \ln (1+B)
$$

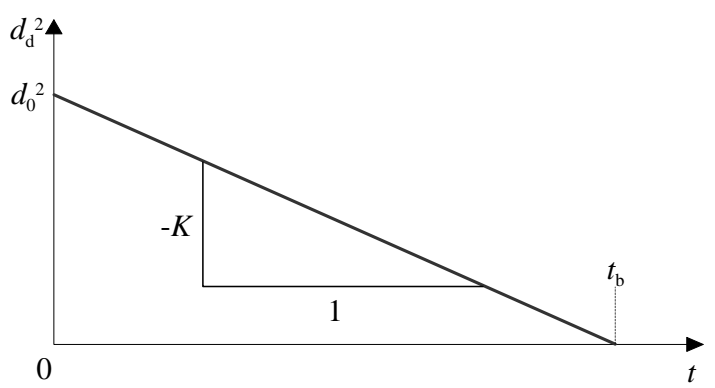

Figure 4. $d^{2}$-law for droplet burning ${ }^{21}$

The simplified $d^{2}$-law for droplet vaporization and combustion can be stated as: ${ }^{21}$

$$
d_{\mathrm{d}}^{2}(t)=d_{0}^{2}-K t
$$

Finally, the total droplet burning time or droplet lifetime $t_{\mathrm{b}}$, defined as the span of time between the first detection of the flame and the flame extinction, which is given for $d_{\mathrm{d}}^{2}\left(t_{\mathrm{b}}\right)=0$ can be evaluated from: ${ }^{21}$

$$
t_{\mathrm{b}}=\frac{d_{0}^{2}}{K}=\frac{\rho_{\mathrm{d}} d_{0}^{2}}{8 D \rho_{\mathrm{g}} \ln (1+B)}
$$

Previous investigations have confirmed the $d^{2}$-law not only for pure hydrocarbon droplets, but also for gelled JP-5, using an organic metallic gellant. ${ }^{18,19}$ However, since the gelling agent increases the latent heat of vaporization and also slightly the propellant density in comparison to the pure ungelled liquid, an increasing amount of gelling agent increases the droplet burning time. Besides a decreased burning rate with increased gelling agent amount, also a higher droplet burning temperature has been measured for increased gelling agent amounts. ${ }^{19}$ 


\section{A. Experimental setup and measurement technique}

For the first gelled droplet experiments, static conditions have been chosen. A surrounding environment providing ambient pressure and temperature has been applied to protect the experiment from disturbing influences (see figure 5). A rectangular acrylic glass housing provides perfect optical access without any distortion. For the droplet burning experiments, droplets of pure or gelled fuel have been suspended by a thin, horizontally arranged thermocouple wire, which was also adjustable in height to meet proper vertical positioning.

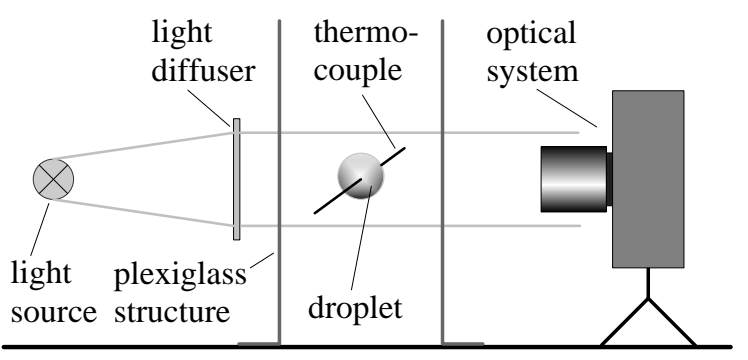

Figure 5. Droplet burning setup

The optical measurement system consisted of a digital black-and-white high speed camera recording with frame rates of $1000 \ldots 2000 \mathrm{fps}$ and an attached $105 \mathrm{~mm} \mathrm{f} / 2.8$ macro lens with an additional 1.4x teleconverter. Different light sources have been installed to backlight the droplets during vaporization and combustion.

Ignition of the droplets has been done by the use of a small propane flame for its simplicity and controllability. The point of ignition has been detected by analyzing single frames of the captured video streams. To minimize the disturbance of the burning behavior due to the thermocouple, a variety of different thermocouple wire diameters in the range of $0.120 \ldots 0.013 \mathrm{~mm}$ was investigated.

\section{B. Droplet temperature}

Figure 6 depicts the droplet temperature $T_{\mathrm{d}}$ during the burning process for pure liquids and gelled propellants. Preliminary investigations show a similar behavior for silica and HPC gels. For pure hydrocarbons and MMH, a raise in temperature is visible after droplet ignition, followed by a region with an almost constant droplet temperature $T_{\mathrm{d}}$. At approximately $80 \%$ of the droplet life time, the flame begins to touch the thermocouple, and the temperature increases. For the MMH a surprisingly low burning temperature of approximately $350 \ldots 375 \mathrm{~K}$ has been measured, which is close to the boiling point (see table 1) The temperature of the burning JP-8 droplets is in the range of $400 \ldots 425 \mathrm{~K}$.

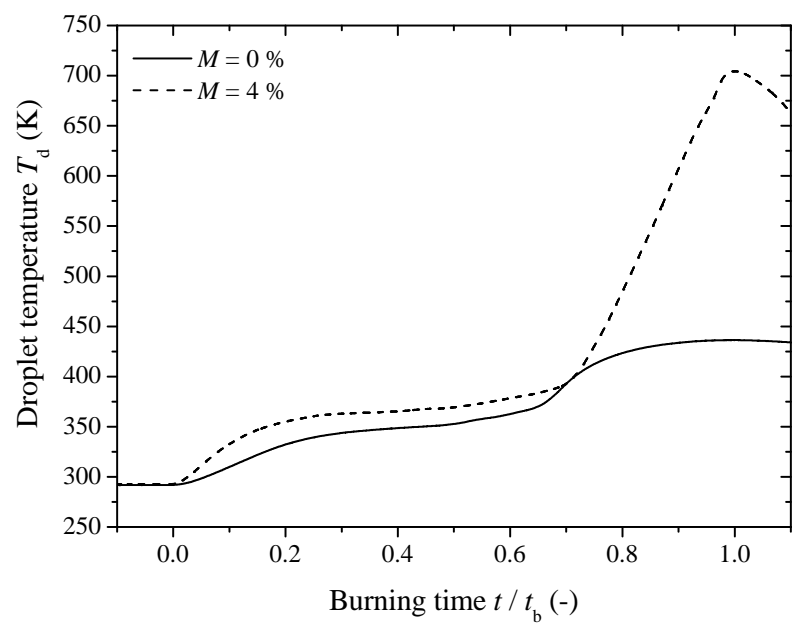

(a) MMH gel

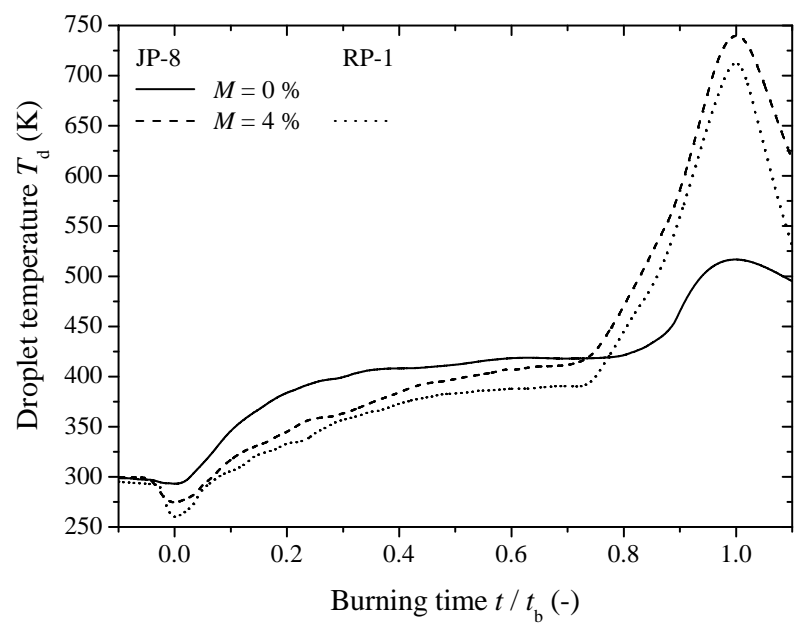

(b) Hydrocarbon gels

Figure 6. Droplet temperature during burning

Gels with a gelling agent amount of $M=4 \%$ show a comparable behavior for the first $75 \%$ of the burning process. For JP-8 and RP-1 a slightly lower temperature in that region has been measured, while the gelled MMH burns at slightly higher temperatures than the pure MMH. The last quarter of the drop burning process is controlled by a steep temperature increase. For the silica/hydrocarbon droplets, the 
fuel entrapped inside the rigid silica shell starts to burn. For the MMH gel, the periodical swelling and diminishing comes to an end when the fuel inside the droplet is burned and the flame starts to touch the thermocouple tip.

\section{Droplet shape and size during burning}

Optical investigations confirmed the different droplet burning of the hydrocarbon/silica and MMH/HPC gels. Hydrocarbon/silica gels showed the production of a more and more rigid and stiff structured during the droplet burning. Because of the stiff, inelastic surface, cracks occur with vapor eruption of the entrapped heated gas. ${ }^{23}$

Due to the viscous, liquid-like outer shell of the MMH/HPC droplet, an almost constant inner pressure leads to swelling and jetting during the combustion. Swelling, vapor or fuel jetting, and size diminishing determine the droplet burning process, which is typical for droplets with organic gelling agents. ${ }^{2}{ }^{20}$ Figure 7 (a) depicts a series of high speed frames for a MMH/HPC droplet featuring an initial diameter of approximately $d_{0}=2 \ldots 2.5 \mathrm{~mm}$. The droplet is ignited at $t_{0}$ (see frame 1). Frames 2 and 3 show a bubble eruption. Within only $2 \mathrm{~ms}$ the bubble eruption is finished at that place and starts somewhere else on the droplet surface. Frames 4 and 5 picture further bubble eruptions at different times after ignition. At the end of the burning process, large bubbles with a very thin outer layer have been captured (see frame 6). The burning of a JP-8/silica droplet is pictured in figure 7 (b). Frame 1 shows the point of ignition. Shortly after that, the clear droplet starts to become blur (see frame 2). At the end of the droplet burning, a stiff, hollow silica structure remains, as shown in frame 3. Due to the droplet burning in air with a temperature below the vaporization temperature of the $\mathrm{HPC}\left(550 \ldots 720 \mathrm{~K}^{7}\right), \mathrm{MMH} / \mathrm{HPC}$ droplets also showed a remaining gelling agent structure after the flame is extinguished. Contrary to the hollow stiff silica structure the unburned $\mathrm{MMH} / \mathrm{HPC}$ gel remain is ductile and elastic.

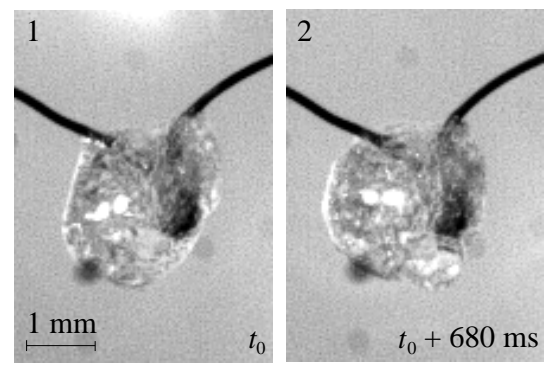

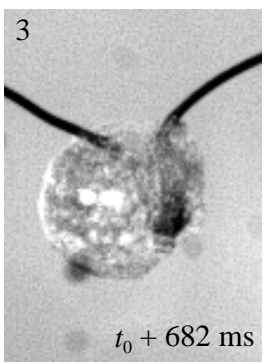

(a) $\mathrm{MMH} / \mathrm{HPC}(M=4 \%)$
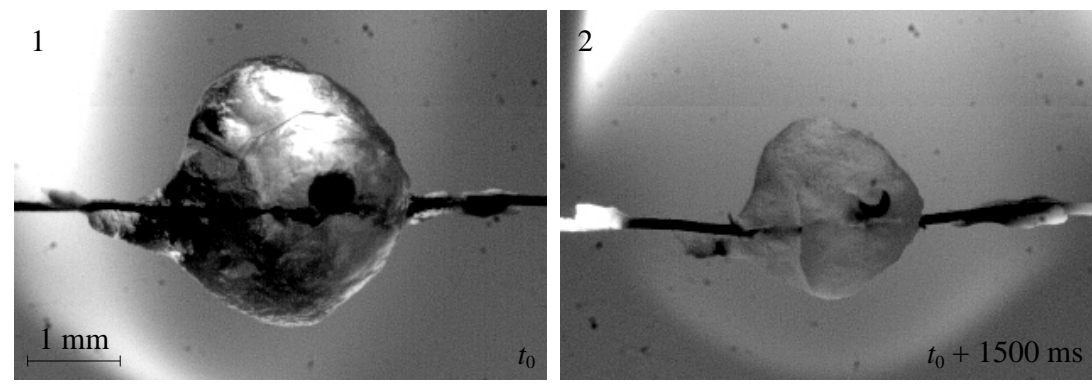

(b) JP-8/silica $(M=4 \%)$

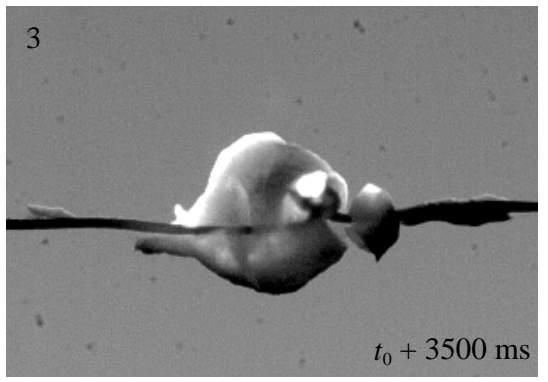

Figure 7. Droplet burning

\section{Burning behavior}

Extensive studies have been performed to investigate droplet burning behavior of gelled JP-8 droplets. ${ }^{23}$ For pure RP-1 and JP-8 droplets agreement with the typical $d^{2}$-law can be stated. The burning of hydrocarbon/silica gel droplets can be described also with the $d^{2}$-law, however some restrictions apply. After an initial period, the gelled droplets burn with a good agreement with the $d^{2}$-law. Due to the inorganic structure of 
the silica, a hollow rigid structure is built, which results in a droplet diameter $\neq 0$ after burn-out, which is also a function of the silica amount. Naturally, the $d^{2}$-law cannot describe this behavior.

However, as depicted in figure 8, gelled JP8 and RP-1 droplets with varying initial square droplet diameters $d_{0}^{2}$ follow the $d^{2}$-law with satisfactorily agreement. Contrary to that, preliminary investigations with MMH/HPC droplet burning, featuring the same amount of gelling agent $(M=4 \%)$, resulted in a much higher burning constant, as pictured in figure 8 . The faster burning of the $\mathrm{MMH} / \mathrm{HPC}$ droplets can be explained to some extent by a different heat of combustion. The heat of combustion for pure RP-1 and JP-8 is approximately $43 \mathrm{MJ} / \mathrm{kg},{ }^{24}$ and for pure MMH $28.3 \mathrm{MJ} / \mathrm{kg}$. ${ }^{4}$ Since the burning constant $K$ is a direct function of the Spalding number (see equation 11), which is reciprocal to the heat of combustion. A lower heat of combustion directly results in a faster droplet burning. But other parameters like heat capacity, density, and vapor pressure also influences

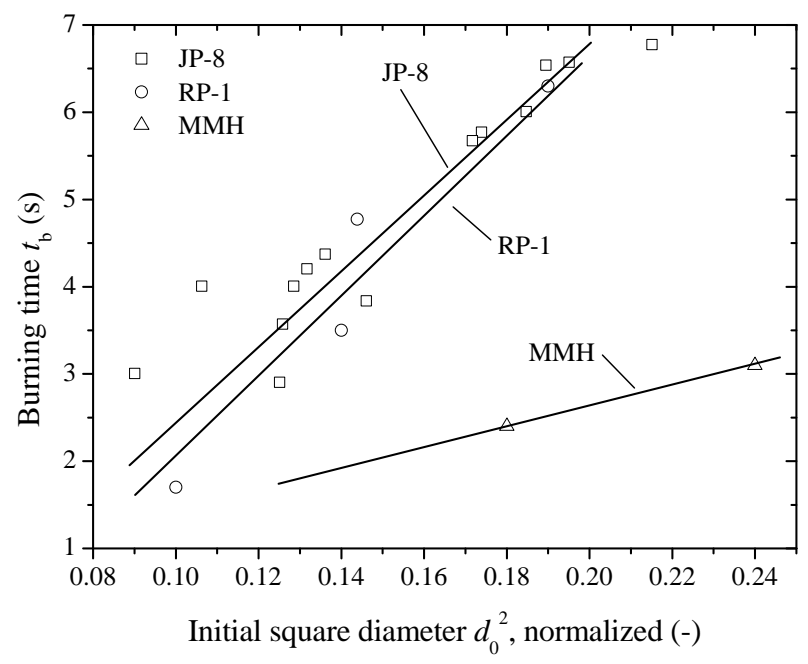

Figure 8. Droplet burning behavior $(M=4 \%)$ the burning behavior.

\section{Conclusions}

Within the present study, hydrocarbon/silica and MMH/HPC gels have been investigated in terms of rheology and droplet burning. Rheological measurements showed the different character of the gels. Hydrocarbon/silica gels with a yield stress can be described with a Herschel-Bulkley model, whereas MMH/HPC gels featured a Newtonian plateau without yield stress, which can be represented with the model from Carreau-Yasuda. MMH/HPC droplets showed a faster burning then the hydrocarbon/silica drops with a comparable droplet temperature during burning. Optical investigations confirmed the different burning behavior of gels using silica and HPC as a gelling agent. Silica remains unburned at the end with a hollow, rigid structure that builds cracks with vapor eruption during combustion. MMH/HPC droplets showed the typical swelling during combustion. Further detailed studies are planned at Purdue University to delve into the droplet combustion of gelled MMH droplets. A hypergolic droplet burning chamber has been developed recently with allows studies with a NTO oxidizer stream which reacts with the gelled MMH droplets.

\section{Acknowledgement}

The research presented in this paper was made possible with the financial support of the U.S. Army Research Office under the Multi-University Research Initiative (MURI) grant number W911NF-08-1-0171.

\section{References}

\footnotetext{
${ }^{1}$ Pein, R., "Gel Propellants and Gel Propulsion," 5th International High Energy Materials Conference and Exhibit DRDL, Hyderabad, India, November 23rd-25th 2005.

${ }^{2}$ Solomon, Y., Natan, B., and Cohen, Y., "Combustion of Gel Fuels Based on Organic Gellants," Combustion and Flame, Vol. 156, 2009, pp. 261-268.

${ }^{3}$ Hodge, K., Crofoot, T., and Nelson, S., "Gelled Propellants for Tactical Missile Applications," 35th AIAA/ASME/ SAE/ASEE Joint Propulsion Conference 83 Exhibit, Los Angeles, CA, June 20th-23rd 1999, AIAA 99-2976.

${ }^{4}$ Schmidt, E. W., Hydrazine and its Derivatives: Preparation, Properties, Applications., Vol. 1, John Wiley \& Sons, Inc., second edition ed., 2001.

${ }^{5}$ Rahimi, S., Hasan, D., Peretz, A., Benenson, Y., and Welner, S., "Preparation and Characteristics of Gel Propellants and Simulants," 37th AIAA/ASME/SAE/ASEE Joint Propulsion Conference and Exhibit, Salt Lake City, UT, July 8th-11th 2001, AIAA 2001-3264.

${ }^{6}$ Rahimi, S., Hasan, D., and Peretz, A., "Development of Laboratory-Scale Gel-Propulsion Technology," Journal of Propulsion and Power, Vol. 20, No. 1, January-February 2004, pp. 93-100.
} 

2001.

${ }^{7}$ Hercules Incorperated, "KLUCEL Hydroxypropylcellulose-Physical and Chemical Properties," Technical Information,

${ }^{8}$ Hercules Incorperated, "KLUCEL Hydroxypropylcellulose, Food Grade-Summary of Properties and Uses," Technical Information, 2003, Product Data No. 4225.

${ }^{9}$ Arnold, R., Santos, P. H. S., Kubal, T., Campanella, O., and Anderson, W. A., "Investigation of Gelled JP-8 and RP-1 Fuels," International Conference on Chemical Engineering (ICCE'09) within The World Congress on Engineering and Computer Science 2009 (WCECS 2009), San Francisco, CA, October 20th-22nd 2009, Published in Proceedings of the World Congress on Engineering and Computer Science 2009, Vol I, ISBN 978-988-17012-6-8, pp. 63-68.

${ }^{10}$ Sutton, G. P., "History of Liquid-Propellant Rocket Engines in Russia, Formerly the Soviet Union," Journal of Propulsion and Power, Vol. 19, No. 6, 2003, pp. 1008-1037.

${ }^{11}$ Coguill, S. L., "Synthesis of Highly Loaded Gelled Propellants," Tech. rep., Resodyn Corporation, Butte, MT, 2009.

${ }^{12}$ Rapp, D. C. and Zurawski, R. L., "Characterization of Aluminium/RP-1 Gel Propellant Properties," 24th AIAA/ASME/ SAE/ASEE Joint Propulsion Conference, Boston, MA, July 11th-13th 1988, AIAA-88-2821.

${ }^{13}$ Ferguson, J. and Kemblowski, Z., Applied Fluid Rheology, Elsevier Science Publishing Co., Inc., New York, NY, 1991.

${ }^{14}$ Madlener, K. and Ciezki, H., "Analytical Description of the Flow Behavior of Extended Herschel-Bulkley Fluids with Regard to Gel Propellants," 36th International Annual Conference of ICT 83 32nd International Pyrotechnics Seminar, Karlsruhe, Germany, June 28th-July 1st 2005.

${ }^{15}$ Ciezki, H. K. and Natan, B., "An Overview of Investigations on Gel Fuels for Ramjet Applications," ISABE2005, 17th Int. Symposium on Airbreathing Engines, Munich, Germany, September 4th-9th 2005.

${ }^{16}$ Rahimi, S. and Natan, B., "Atomization Characteristics of Gel Fuels," 34th AIAA/ASME/SAE/ASEE Joint Propulsion Conference \& Exhibit, Cleveland, OH, July 13th-15th 1998, AIAA 98-3830.

${ }^{17}$ Bar-or, D. and Natan, B., "Experimental Evaluation of Gel Fuel Droplet Burning Rates at Sub and Supercritical Conditions," 44th AIAA/ASME/SAE/ASEE Joint Propulsion Conference /E Exhibit, Hartford, CT, July 21st-23rd 2008, AIAA 2008-4874.

${ }^{18}$ Nahamoni, G. and Natan, B., "Investigation of the Combustion Process of Gel Propellants," 33rd AIAA/ASME/ SAE/ASEE Joint Propulsion Conference and Exhibit, Seattle, WA, July 6th-9th 1997, AIAA-1997-2973.

${ }^{19}$ Nachmoni, G. and Natan, B., "Combustion Characteristics of Gel Fuels," Combustion Science and Technology, Vol. 156, 2000, pp. 139-157.

${ }^{20}$ Solomon, Y. and Natan, B., "Experimental Investigation of the Combustion of Organic-Gellant-Based Gel Fuel Droplets," Combustion Science and Technology, Vol. 178, 2006, pp. 1185-1199.

${ }^{21}$ Turns, S. R., An Introduction to Combustion-Concepts and Applications, McGraw-Hill Series, 2nd ed., 2000.

${ }^{22}$ Natan, B. and Rahimi, S., "The Status of Gel Propellants in Year 2000," Combustion of Energetic Materials, Kuo, K. K. and deLuca, L., 2001.

${ }^{23}$ Arnold, R. and Anderson, W. E., "Droplet Burning of JP-8/Silica Gels," 48th AIAA Aerospace Sciences Meeting, Orlando, FL, January 4th-7th 2010, AIAA-2010-0421.

${ }^{24}$ Coordinating Research Council, "Handbook of Aviation Fuel Properties," Tech. rep., Coordinating Research Council, Inc., Alpharetta, GA, 2004, CRC Report No. 635. 